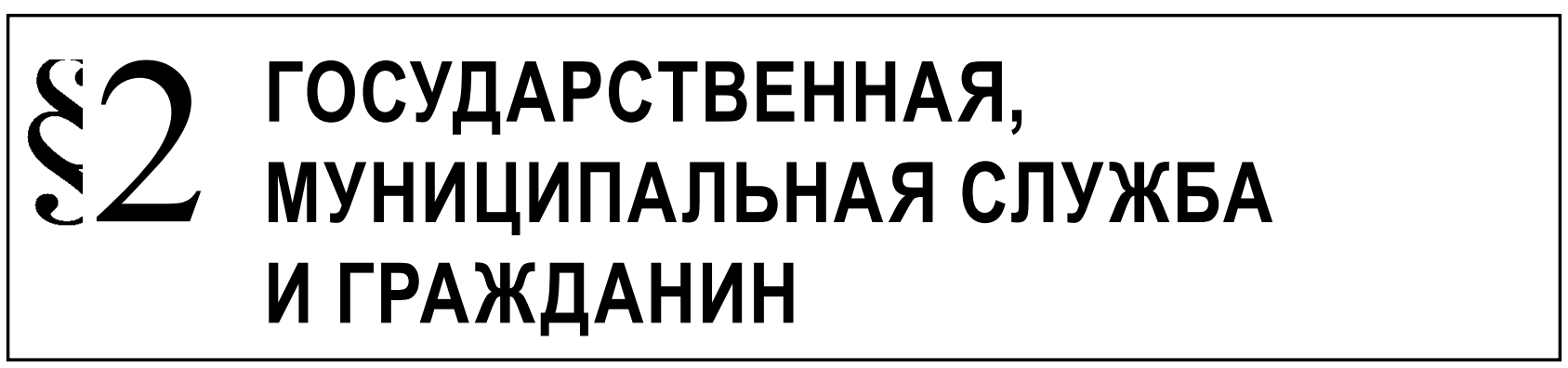

Мещерягина В.А.

\title{
КОНСТИТУЦИОННОЕ ПРАВО НА ОБРАЩЕНИЕ КАК ЭЛЕМЕНТ ПОДДЕРЖАНИЯ БАЛАНСА ИНТЕРЕСОВ ЛИЧНОСТИ, ОБЩЕСТВА И ГОСУДАРСТВА
}

Аннотация. В данной статье конституционное право на обращение рассматривается как правовая форма диалектического взаимодействия интересов государства, общества и личности. Обозначается спектр нерешенных теоретико-правовых и практических вопросов, совокупность которых препятствует развитию института конституционного права на обращение в Российской Федерации. Выдвигаются конкретные предложения по повышению качества законодательного регулирования института конституционного права на обращение, которые могут стать положительным импульсом для дальнейшего развития института конституционного права на обращение, обновления системы государственного управления в целом. В исследовании использовались общенаучные, частнонаучные методы познания, которые включают в себя такие методы, как системный метод, синтез, нормативно-логический метод, анализ, дедукция, индукция и иные методы научно-исследовательской деятельности. Основными выводами проведенного исследования являются: необходимость закрепления и раскрытия в федеральном законодательстве понятия "петиция»; установления инстанционности для досудебных обращений, в рамках которой предлагается обязать гражданина направлять обращение изначально в муниципальные органы власти, подразделения государственных органов в соответствующем муниципальном образовании или субъекте; обязать гражданина указывать в обращении факт направления одного и того же обращения в несколько органов власти, иные организации.

Ключевые слова: право на обращение, обращение, законный интерес, петиции, законотворческая инициатива, публичный интерес, интерес личности, референдум, Конституционный Суд России, коллективные обрамения.

Review. The article considers the constitutional right to appeal as a legal form of dialectical correlation between the interests of the state, the society and a person. The author outlines the range of unsettled theoretical-legal and practical questions, hindering the development of institution of the constitutional right to appeal in the Russian Federation. The author puts forward concrete suggestions about the enhancement of legislative regulation of the institution of the constitutional right to appeal and the renewal of the system of public management in general. The author applies the general scientific and the special scientific methods of research, including the systems method, synthesis, the normative-logical approach, analysis, deduction, induction and other methods. The author comes to the conclusion about the need for legitimation and explanation of the notion "petition" in federal legislation; establishment of instance for pre-trial appeals thus obliging a citizen to address an appeal primarily to municipal authorities and municipal branches of public bodies; obliging a citizen to notify the fact of copying the same appeal to several government bodies and other organizations.

Keywords: personal interest, public interest, legislative initiative, Petitions, legal interest, appeal, right to appeal, referendum, The Constitutional Court Of Russia, collective appeals.

$\mathrm{B}$ условиях современного демократического развития Российской Федерации все более актуализируются вопросы, связанные с балансом интересов (под категорией «интерес» в настоящей статье понимается опосредованный внешними условиями, внутренними (внутрисистемными) факторами процесс формирования и оформления потребностей как побудительного 
начала субъекта к их последующему удовлетворению в рамках общественных отношений.) органов государственной власти, личности и общества, как субъектов конституционных правоотношений.

Конституция Российской Федерации (далее по тексту - Конституция РФ) закрепляет спектр основополагающих правовых норм и институтов в иерархическом порядке. На первый взгляд, определить концепт «диалога» вышеуказанных субъектов, приоритет отдельных конституционно-правовых отношений, не представляет существенных затруднений.

Тем не менее, несмотря на внешнюю «стройность» норм Конституции РФ, соблюсти баланс интересов личности, общества и органов государственной власти на практике достаточно проблематично. Это явление имеет широкий спектр причин, к которым относятся как теоретико-правовые (трудности сопоставления интересов индивидуального и коллективного субъектов в рамках конституционных правоотношений, существующие коллизии и пробелы правовой системы России, развитая система подзаконного регулирования общественных отношений и т.д.), так и практические (особенности внутренней самоорганизации и функционирования государственных органов, перегруженность последних, бюрократизм, статичность права по отношению к быстроразвивающимся общественным отношениям и т.д.).

Как верно заметил Зорькин В.Д.: «Конституция действует не в идеальной среде, а в противоречивой действительности. Главное - обеспечить оптимальное соотношение принципов и норм Конституции к реальности в тот, или иной конкретноисторический период развития страны» [7,].

Конституция РФ содержит несколько базовых элементов, обеспечивающих сбалансированность между личностью, обществом и органами государственной власти в реализации своих интересов. При этом ключевым является, закрепленное в ст. 33 Конституции РФ право на обращение: «Граждане Российской Федерации имеют право обращаться лично, а также направлять индивидуальные и коллективные обращения в государственные органы и органы местного самоуправления».

Следует согласиться с позицией Карасева А.T.: «Права человека - это обеспеченные законом возможности для удовлетворения жизненных потребностей, интересов, получения социальных благ» [8, c.12]. В данной связи конституционное право на обращение предстает как неотъемлемое субъективное право человека и сообразовывается с осно- вополагающей нормой-принципом: «человек, его права и свободы являются высшей ценностью» (ст. 2 Конституции РФ).

Ценность конституционного права на обращение выражается в возможности личности участвовать в широком спектре политических, социальных, экономических, и иных общественных отношений, направленных на реализацию, защиту и восстановление своих прав и интересов, прав и интересов других лиц.

В ч. 1 и 2 ст. 3 Конституции РФ указано: носителем суверенитета и единственным источником власти в Российской Федерации является ее многонациональный народ. Народ осуществляет свою власть непосредственно, а также через органы государственной власти и органы местного самоуправления. По верному замечанию Казьминой Е.А., народ - не простая толпа, а группа лиц, объединенных общим интересом, такой интерес и формируется в единую общую волю народа [10, с.122].

Таким образом, народ объединяет в себе общности, сгруппированные для реализации интересов различной направленности. Примером выражения публичности интереса являются выборы и референдумы, тем более в ч. 3 ст. 3 Конституции РФ указанные формы волеизъявления - высшее непосредственное выражение власти народа.

Процедура проведения выборов инициируется органами власти, имеет широкий перечень для субъектов, узкую направленность рассматриваемых вопросов (формирование органа государственной власти, органа местного самоуправления или наделения полномочиями должностного лица). Референдум не лишен вышеуказанных недостатков несмотря на то, что круг рассматриваемых вопросов заметно шире (наиболее важные вопросы государственного и местного значения), таким образом, конституционное право на обращение является более эффективной возможностью реализации публичного интереса, более того, оно не только принадлежит коллективными субъектами, но и отдельной личности. Показательно, что при расширительном толковании права на обращение как волеизъявления гражданина [16, с.1345], оно является основой процедурного механизма проведения референдума (уведомление о вопросе (вопросах) референдума, избирательный бюллетень и т.д.).

Преимущество конституционного права на обращение прослеживается даже в историческом разрезе. Авакьян С.А. констатирует: «Исторически референдумы возникли как форма обращения власти к народу с просьбой высказаться, сообщить свое 
мнение по возникшей проблеме» [2, с.416]. Алистратов Ю.Н. замечает: институт обращений граждан в государственные органы возник как естественная реакция отдельных слоев населения на деспотизм авторитарной власти, он не сразу получил правовое закрепление, а первоначально существовал как стихийное социальное движение [3, c.46].

Как уже было отмечено выше, реализуя конституционное право на обращение гражданин может возвести свой личный интерес в степень публичного (соответственно, в правовую плоскость тоже), самостоятельно: например, посредством направления предложения - рекомендации гражданина по совершенствованию законов и иных нормативных правовых актов как на местном, так и на общефедеральном уровнях.

Автором предлагается также рассматривать в качестве специфических форм влияния гражданина на правовую систему и приведения личного интереса в публичный посредством направления обращений в Конституционный Суд Российской Федерации (далее по тексту - Конституционный Суд РФ) и направления обращений в Министерство Юстиции Российской Федерации (далее по тексту Минюст РФ).

Конечно, понимание юридической природы решений Конституционного Суда РФ неоднозначно как в теории права, так и в правоприменительной практике, но бесспорным является тот факт, что указанные решения имеют существенное влияние на все отрасли российского права, являются импульсом его развития, стимулируют актуальность Конституции РФ для уже существующих и развивающихся общественных отношений. Правовые позиции Конституционного Суда РФ обязательны для исполнения всеми субъектами и применяются ко всем сходным отношениям.

В качестве примера приведем Постановление Конституционного Суда РФ от 16 декабря 2014 № 33-П, в связи с жалобой гражданина Н.В. Гончарова, в котором Конституционный Суд РФ постановил пересмотреть правоприменительные решения, вынесенные в отношении указанного гражданина, касающиеся порядка распределения депутатских мандатов, ставших вакантными в связи с досрочным прекращением полномочий депутатов Государственной Думы. Этим решением Конституционный Суд РФ обязал федерального законодателя внести необходимые изменения в правовое регулирование отношений, связанных с распределением вакантных депутатских мандатов в случае досрочного прекращения полномочий депутатов
Государственной Думы, указав, что Законы субъектов Российской Федерации, законоположения либо воспроизводящие их или содержащие такие же положения, какие были признаны не соответствующими Конституции РФ, подлежат отмене в установленном порядке.

Во втором случае, в органы Минюста РФ граждане могут направлять различные виды обращений: как предложения по совершенствованию законов и иных нормативных правовых актов, так и жалобы на пробелы в законодательстве (без проработки конкретных предложений по их регулированию). Это возможно в связи со специфическими полномочиями министерства, содержащиеся в Указе Президента РФ от 13 октября 2004 г. № 1313, к числу которых относятся:

1. проведение правовой экспертизы проектов законодательных и иных нормативных правовых актов, вносимых федеральными органами исполнительной власти на рассмотрение Президента Российской Федерации и Правительства Российской Федерации, а также проектов концепций и технических заданий на разработку проектов федеральных законов;

2. подготовка проектов официальных отзывов и заключений на проекты федеральных конституционных законов и федеральных законов, а также проектов поправок к ним;

3. разработка и представление в Правительство Российской Федерации по его поручению предложения о приоритетных направлениях законопроектной деятельности Правительства Российской Федерации, а также проекты планов законопроектной деятельности Правительства Российской Федерации;

4. обобщение практики подготовки федеральными министерствами проектов федеральных конституционных законов и федеральных законов, осуществление методического обеспечения их подготовки;

5. координация работы федеральных органов исполнительной власти по подготовке предложений к проектам планов законопроектной деятельности Правительства Российской Федерации и подготовка правовых заключений о целесообразности разработки законопроектов;

6. осуществление государственной регистрации нормативных правовых актов федеральных органов исполнительной власти, затрагивающих права, свободы и обязанности человека и гражданина, устанавливающих правовой статус организаций или имеющих межведом- 
ственный характер, а также актов иных органов в случаях, предусмотренных законодательством Российской Федерации.

О конституционном праве на обращение как возможности реализации коллективными субъектами своих публичных интересов в научной литературе говорилось достаточно много. В основном, данную возможность связывают с так называемым «правом петиции» - разновидности коллективного обращения.

В настоящее время в российской провой системе отсутствует определение коллективных обращений. Что касается «права петиции», ситуация еще более парадоксальная: ни определения, ни упоминания данной категории федеральное законодательство не содержит (если не считать случайного, по нашему мнению упоминания слова «петиция» в Федеральном законе от 10 января 2002 г. № 7-Ф3 «Об охране окружающей среды»), тем не менее, данное наименование активно присваивается коллективным обращениям гражданам в правотворческой практике субъектов России.

При характеристике петиции, как разновидности коллективного обращения в России, ученыеконституционалисты выделяют:

1) Предмет петиции: вопросы, имеющие общественное значение (проведение реформ, внесение изменений в законодательство, совершенствование общественного устройства и др.) [11, с.15], публичные проблемы, интересы всего государства или его субъектов [12, c.15]. Ряд авторов трактуют понятие предмета петиции более широко, включая жалобы на действия органов и должностных лиц органов государственной власти и местного самоуправления, предложения о рассмотрении какого-либо вопроса, имеющего общественное значение на определенной территории, коллективное требование отчета руководителя органа государственной власти или местного самоуправления [14, с.1345]. Авакьян С.А. поясняет, что коллективные обращения по вопросам общественного значения изначально связывались с предложениями граждан, но в последние годы стали именоваться петициями [2, с.481]. Косолапов А.В. отождествляет петиции с коллективными жалобами, называя их средством правовой политики [9, с.223].

2) Форму петиции: исключительно письменную [11, c.106].

3) Инициативную группу для подачи петиции (от десяти до трехсот человек; одного процента от числа граждан, обладающих активным избирательным правом и т.д.). Последнее, например, содержится в ч. 1 ст. 54 Устава (Основного закона) Томской области, принятого решением Томской областной Думы от 26 июля 1995 г. № 136.

4) Определенный круг адресатов петиции.

5) Особая процедура подачи и рассмотрения, например Миронов М.А. указывает, что в петициях поднимаются не частные, а общественно значимые публичные вопросы, для которых должен быть установлен особый порядок выдвижения, направления и рассмотрения) [12, c.16].

Аналогичный подход к пониманию петиции наблюдается в толковых словарях, где петиция это «коллективное письменное прошение, подаваемое главе правительства или высшим органам власти» [6, с.255]; «коллективная просьба в письменной форме, обращенная к властям» [15, с.673]; «официальная коллективная просьба, ходатайство, обращенное к органу государственной власти, высшему начальству» $[19$, с.342].

В действующем федеральном законодательстве уже имеется правовая конструкция, отвечающая всем вышеуказанным признакам - законотворческая инициатива граждан, правотворческая инициатива, т.е. осуществляемое на местном уровне, официальное внесение проектов нормативных правовых актов группой граждан в установленном законом порядке во властные органы (Трофимов B.B. называет ее петицией, которая инициирует проведение народного референдума) [18, с.463].

Фактически, различия между петицией и правотворческой инициативой граждан заключаются в уровнях реализации - последней свойственен только региональному и местному уровням.

Официальное признание этой формы участия населения в осуществлении местного самоуправления, в качестве разновидности конституционного права на обращение (например - специального вида предложения) способствовало бы усилению правовых гарантий реализации народом своей власти (Схожий подход имеется в регионально законодательстве: в ст. 20 Устава муниципального образования «Город Калуга» от 23 декабря 1997 г. № 215, указано, что граждане, осуществляющие народную правотворческую инициативу, обращаются в городскую Думу с предложением о принятии, изменении или отмене правового акта). Особенно это актуально для процедурных аспектов рассмотрения и принятия решения по правотворческой инициативе граждан, так как в ч. 3 ст. 26 Феде- 
рального закона Российской Федерации от 6 октября 2003 г. № 131-Ф3 «Об общих принципах организации местного самоуправления в Российской Федерации» подробная регламентация сроков и порядка рассмотрения правотворческой инициативы граждан оставлена на усмотрение органов местного самоуправления (Указано только, что мотивированное решение, принятое по результатам рассмотрения проекта муниципального правового акта, внесенного в порядке реализации правотворческой инициативы граждан, должно быть официально в письменной форме доведено до сведения внесшей его инициативной группы граждан).

В региональном законодательстве прослеживается смешение категориального аппарата права на обращение. В Уставе города Москвы от 28 июня 1995 г. употребляется понятие «петиция», которое представляет собой гражданскую законодательную инициативу, направляемую в виде петиции с предложением о принятии, изменении или отмене закона города Москвы.

В ч. 3 ст. 54 Устава Томской области указано, что гарантируется право на коллективные обращения в органы государственной власти с письменными петициями об осуществлении законодательных, исполнительных или судебных мер по вопросам, затрагивающим их интересы.

Итак, конституционное право на обращение представляет собой эффективный механизм реализации своих интересов как личностью, так и коллективами граждан, тем самым имея существенное значение для соблюдения баланса данных интересов, с определяющим значением органов государственной власти.

Функциональное содержание государства по своей природе антагонично, так в соответствии со ст. 2 Конституции РФ: «...Признание, соблюдение и защита прав и свобод человека и гражданина обязанность государства», но согласно ч. 3 ст. 55 Конституции РФ, права и свободы человека и гражданина могут быть ограничены в целях защиты прав и законных интересов других лиц, обеспечения обороны страны и безопасности государства.

В Постановлении Конституционного Суда РФ от 16 июля 2004 г. № 14 - П по делу о проверке конституционности отдельных положений ч.2 ст. 89 НК РФ, в связи с жалобами граждан А.Д. Егорова и Н.В. Чуева сказано: «Российская Федерация как демократическое федеративное правовое и социальное государство, действуя в интересах всего общества в целях соблюдения и защиты прав и свобод человека и гражданина как высшей ценности, осу- ществляет социальную, экономическую, правоохранительную и другие функции».

Государственный интерес связан с обеспечением собственной безопасности, через призму интересов всего общества соблюдает и защищает права и свободы человека и гражданина. Для реализации этих функций государство располагает собственным аппаратом управления - государственными органами [4, с.27].

По мнению Е.Ю. Добрынина: «Интерес государства - как источник социальной функции - приравнивается в первую очередь к группе факторов работающих на сохранение и усиление мощи организации публичной власти» [5, c.64]. М.С. Матейкович, Горбунов В.А. считают, что органы государства образуют единую систему, в которой создается механизм самообслуживания и саморегуляции, посредством этого механизма обеспечивается функционирование рассматриваемого субъекта $[13$, c.66].

В результате, государственный интерес включает в себя такую категорию, как ведомственный интерес. Некоторые ученые считают, что многообразие и противоречивость интересов, возможности ими манипулировать, приводят к тому, что государственный интерес зачастую преобразуется в ведомственный, а последний - в групповой или личный. Одной из характерных черт этого процесса является стремление к засекречиванию деятельности [1, с.87].

Именно по этим причинам, возможность направления обращений в любые государственные и муниципальные учреждения, иные организации, осуществляющие публично значимые функции позволяет гражданам реализовать общественный контроль за деятельностью последних (в данном случае речь идет, в том числе, о возможности направления обращения в виде запроса в соответствии с Федеральным законом от 09.02.2009 № 8-ФЗ «Об обеспечении доступа к информации о деятельности государственных органов и органов местного самоуправления»).

Однако не стоит трактовать понятие ведомственного интереса исключительно с негативной стороны. В научной литературе не раз подчеркивалось, что органы исполнительной власти крайне заинтересованы в анализе поступающих обращений, выявляя проблемы и несовершенство направлений своей деятельности.

Тем не менее, несмотря на то, что право граждан на обращение имеет одной из своих целей оптимизацию деятельности органов государ- 
ственной власти (о чем, в частности говориться в Постановлении Конституционного Суда РФ от 18 июля 2012 № 19-П), зачастую граждане могут злоупотреблять рассматриваемым правом, направляя обращение по одному и тому же вопросу сразу в несколько органов, либо сразу в высшие федеральные органы власти и т.д. Это наводит на мысль о необходимости выработки дополнительных механизмов защиты ведомственного интереса - возможности установления инстанционности рассмотрения внесудебных обращений, что не исключает их последующего обжалования в вышестоящем органе. Для иных типов обращений, (имеющих публично значимую ориентацию) напротив, следует закрепить правило о направлении их высшим должностным лицам, в высшие федеральные органы власти.

Синтезируя все вышесказанное, можно согласиться с мнением В.В. Субочева: «Государственный интерес объединяет в себе два взаимоисключающих начала. Он может и должен в определенных случаях противоречить общественному, гарантируя право каждого. И наконец - взаимоисключать общественный и личный интерес не только ради единичного либо общего блага, но и ради блага своего, блага аппарата управления». Интересы всех трех уровней взаимообуславливают друг друга, модифицируют триединую систему изнутри под влиянием самодостаточных внутрисистемных факторов. Однако именно это зачастую и является ограничением полноты их удовлетворения [17, с.368].

Таким образом, право граждан на обращение занимает в системе конституционных прав осо- бое положение, так как выступает правовой формой диалектического взаимодействия интересов государства, общества и личности, в том числе способствуя возведению законного интереса в степень субъективного права. Поэтому повышение качества законодательного регулирования института конституционного права на обращение может стать положительным импульсом для дальнейшего развития и защиты иных конституционных прав граждан, обновления системы государственного управления в целом.

Для этого необходимо принять следующие меры:

1) Закрепить и раскрыть понятие «петиция» в федеральном законодательстве. Это внесет ясность для правоприменятиеля и оптимизирует порядок работы с обращениями в высших органах государственной власти. В качестве одного из вариантов указанного определения можно предложить: петиция - направленное в письменной форме коллективное обращение с целью урегулирования наиболее важных общественно-политических вопросов.

2) Предусмотреть инстанционность для досудебных обращений, в рамках которой обязать гражданина направлять обращение изначально в муниципальные органы власти, подразделения государственных органов в соответствующем муниципальном образовании или субъекте.

3) Обязать гражданина указывать в обращении о факте направления одного и того же обращения в несколько органов власти, иные организации.

\section{Библиография:}

1. Алексеев С.С. Общая теория права. М., 2008. С. 87

2. Авакьян С. А. Конституционное право России. М., 2011. С. 416-481

3. Алистратов Ю. Н. Право граждан на обращение в органы публичной власти и органы местного самоуправления в условиях становления демократического правового государства в России: дис... канд. юрид. наук. Спб., 1997. С. 46

4. Абдулаев М. И. Теория государства и права. М., 2004. С. 27

5. Добрынин Е.Ю. Соотношение интересов государства, общества и личности в процессе реализации социальной функции государства // Вестник Южно-Уральского Государственного Университета. № 13. 2006. С. 64

6. Ефремова Т.Ф. Толковый словарь русского языка. М., 2009. С. 255

7. Зорькин В.Д. Современный мир, право и Конституция. М., 2010. С. 544

8. Карасев А.Т. Конституционное право Российской Федерации. Общая характеристика основных положений. Екатеринбург, 1998. С. 12

9. Косолапов А.В. Жалоба как правовое средство: понятие и виды. // Вестник Волгоградского государственного университета. 2011. № 2. С. 223

10. Казьмина Е.А. Правосубъектность народа Российской Федерации // Мир науки, культуры, образования. 2011. № 4-2. С. 122

11. Лыскова Е.И. Право граждан на обращение в органы публичной власти: теория и практика // Государство и право. 2009. С. 105-106 
12. Миронов М.А. России нужен закон о петициях // Конституционное и муниципальное право. 2014. № 6. С. 15-16

13. Матейкович М.С., Горбунов В.А. Законные интересы в конституционном праве. М., 2011. С. 66

14. Нуденко Л.А. Концепция Федерального закона «О петициях граждан Российской Федерации» // Конституционное и муниципальное право. 2007. № 6. С. 17

15. Ожегов С.И. Толковый словарь русского языка. М., 2010. С. 673

16. Савоськин А.В. Система обращений граждан в соответствии с объективной стороной волеизъявления граждан РФ (подсистемы устных, письменных и конклюдентных обращений) // Актуальные проблемы российского права. 2014. № 7. С. 1345

17. Субочев В.В. Законные интересы. М., 2012. С. 362-380.

18. Трофимов В.В. Современные формы участия Российского гражданского общества в правотворческом процессе: проблемы теории, законодательной регламентации и практики применения // Юридическая техника. № 8. 2014. С. 463

19. Ушаков Д.Н. Толковый словарь русского языка. М., 1948. С. 342

\section{References (transliterated):}

1. Alekseev S.S. Obshchaya teoriya prava. M., 2008. S. 87

2. Avak'yan S. A. Konstitutsionnoe pravo Rossii. M., 2011. S. 416-481

3. Alistratov Yu. N. Pravo grazhdan na obrashchenie v organy publichnoi vlasti i organy mestnogo samoupravleniya $\mathrm{v}$ usloviyakh stanovleniya demokraticheskogo pravovogo gosudarstva v Rossii: dis... kand. yurid. nauk. Spb., 1997. S. 46

4. Abdulaev M. I. Teoriya gosudarstva i prava. M., 2004. S. 27

5. Dobrynin E.Yu. Sootnoshenie interesov gosudarstva, obshchestva i lichnosti v protsesse realizatsii sotsial'noi funktsii gosudarstva // Vestnik Yuzhno-Ural'skogo Gosudarstvennogo Universiteta. № 13. 2006. S. 64

6. Efremova T.F. Tolkovyi slovar' russkogo yazyka. M., 2009. S. 255

7. Zor'kin V.D. Sovremennyi mir, pravo i Konstitutsiya. M., 2010. S. 544

8. Karasev A.T. Konstitutsionnoe pravo Rossiiskoi Federatsii. Obshchaya kharakteristika osnovnykh polozhenii. Ekaterinburg, 1998. S. 12

9. Kosolapov A.V. Zhaloba kak pravovoe sredstvo: ponyatie i vidy. // Vestnik Volgogradskogo gosudarstvennogo universiteta. 2011. № 2. S. 223

10. Kaz'mina E.A. Pravosub"ektnost' naroda Rossiiskoi Federatsii // Mir nauki, kul'tury, obrazovaniya. 2011. № 4-2. S. 122

11. Lyskova E.I. Pravo grazhdan na obrashchenie v organy publichnoi vlasti: teoriya i praktika // Gosudarstvo i pravo. 2009. S. 105-106

12. Mironov M.A. Rossii nuzhen zakon o petitsiyakh // Konstitutsionnoe i munitsipal'noe pravo. 2014. № 6. S. 15-16

13. Mateikovich M.S., Gorbunov V.A. Zakonnye interesy v konstitutsionnom prave. M., 2011. S. 66

14. Nudenko L.A. Kontseptsiya Federal'nogo zakona «O petitsiyakh grazhdan Rossiiskoi Federatsii» // Konstitutsionnoe i munitsipal'noe pravo. 2007. № 6. S. 17

15. Ozhegov S.I. Tolkovyi slovar' russkogo yazyka. M., 2010. S. 673

16. Savos'kin A.V. Sistema obrashchenii grazhdan v sootvetstvii s ob"ektivnoi storonoi voleiz"yavleniya grazhdan RF (podsistemy ustnykh, pis'mennykh i konklyudentnykh obrashchenii) // Aktual'nye problemy rossiiskogo prava. 2014. № 7.S. 1345

17. Subochev V.V. Zakonnye interesy. M., 2012. S. 362-380.

18. Trofimov V.V. Sovremennye formy uchastiya Rossiiskogo grazhdanskogo obshchestva v pravotvorcheskom protsesse: problemy teorii, zakonodatel'noi reglamentatsii i praktiki primeneniya // Yuridicheskaya tekhnika. № 8. 2014. S. 463

19. Ushakov D.N. Tolkovyi slovar' russkogo yazyka. M., 1948. S. 342 